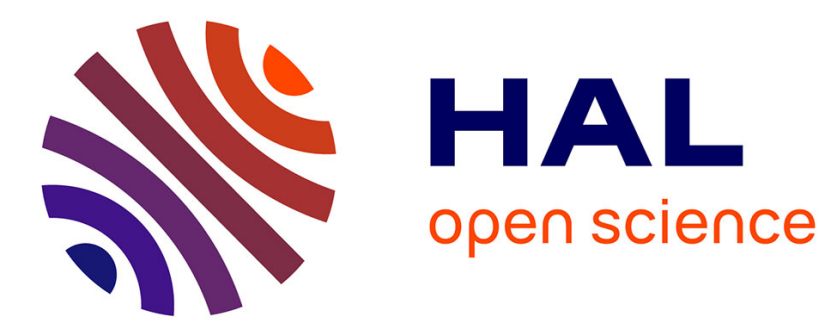

\title{
Development of a Product Design and Supply Chain Fulfillment System for Discontinuous Innovation
}

\author{
John Buffington, Mehdi Amini, Timur Keskinturk
}

\section{To cite this version:}

John Buffington, Mehdi Amini, Timur Keskinturk. Development of a Product Design and Supply Chain Fulfillment System for Discontinuous Innovation. International Journal of Production Research, 2011, 10.1080/00207543.2011.588269 . hal-00715432

\section{HAL Id: hal-00715432 \\ https://hal.science/hal-00715432}

Submitted on 7 Jul 2012

HAL is a multi-disciplinary open access archive for the deposit and dissemination of scientific research documents, whether they are published or not. The documents may come from teaching and research institutions in France or abroad, or from public or private research centers.
L'archive ouverte pluridisciplinaire HAL, est destinée au dépôt et à la diffusion de documents scientifiques de niveau recherche, publiés ou non, émanant des établissements d'enseignement et de recherche français ou étrangers, des laboratoires publics ou privés. 


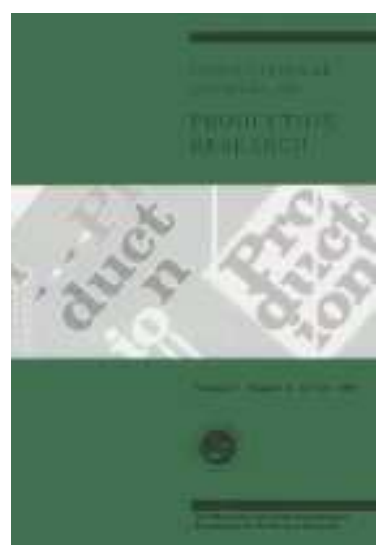

\section{Development of a Product Design and Supply Chain Fulfillment System for Discontinuous Innovation}

\begin{tabular}{|r|l|}
\hline Journal: & International Journal of Production Research \\
\hline Manuscript ID: & TPRS-2011-IJPR-0161 \\
\hline Manuscript Type: & Original Manuscript \\
\hline Author: & $13-$ Seb-2011 \\
\hline Complete List of Authors: & $\begin{array}{l}\text { Buffington, John; Lulea University of Technology, Industrial } \\
\text { Marketing, e-Commerce, and Logistics } \\
\text { Amini, Mehdi; University of Memphis, Marketing and Supply Chain } \\
\text { Management } \\
\text { Keskinturk, Timur; Istanbul University, Business Administration }\end{array}$ \\
\hline Keywords: & $\begin{array}{l}\text { AGENT BASED SYSTEMS, FUZZY METHODS, PRODUCT DESIGN, } \\
\text { INTEGRATION, PRODUCT MODELLING }\end{array}$ \\
\hline Keywords (user): & generative customization, discontinuous innovation \\
\hline
\end{tabular}

\section{SCHOLARONE Manuscripts}




\title{
Development of a Product Design and Supply Chain Fulfillment System for Discontinuous Innovation
}

\author{
Jack Buffington ${ }^{\mathrm{a},}{ }^{*}$ \\ Mehdi Amini ${ }^{a, b}$ \\ Timur Keskinturk ${ }^{c}$

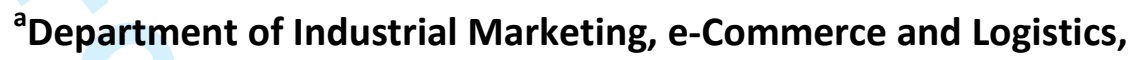 \\ Lulea University of Technology, Lulea, Sweden \\ john.buffington@ltu.se \\ ${ }^{a, b}$ Department of marketing and Supply Chain Management \\ The Fogelman College of Business and Economics \\ University of Memphis \\ Memphis, TN 38153 \\ mamini@memphis.edu \\ c Department of Business Administration \\ Istanbul University \\ Istanbul, Turkey \\ tkturk@istanbul.edu.tr
}




\title{
Development of a Product Design and Supply Chain Fulfillment System for Discontinuous Innovation
}

\begin{abstract}
Given the lengthy product development lifecycle process, high cost, and low success rate, many firms avoid considering discontinuous innovation strategies, in spite of their increase in frequency and importance in many markets. Even with advances in automation and technology, many of the techniques being utilized in product development are relatively unchanged, and the definition of discontinuous innovation itself lacks a structural component.
\end{abstract}

To address this problem, the authors developed a methodology for generative customization to implement discontinuous innovation. Using the emerging technologies of generative design and agent-based modeling, the authors developed a methodology to create product inventions and measure product innovations using a complex adaptive system (CAS) model. This appears to be the first model that represents a complex adaptive system environment to measure the success of discontinuous innovation in the development of a market equilibrium agent model (MEAM).

Keywords: generative customization, discontinuous innovation, product design

\section{Introduction}

Traditionally, a discontinuous innovation has been perceived as a function of a product invention, but for it to occur, dynamic forces from seemingly unrelated processes or industries often must converge upon the environment in order to develop a new consumer market. For instance, an Apple iPod is a discontinuous innovation, less as a function of its ability to store digital music files on a portable hard drive system, and more due to its ability to transform within processes and behaviors via supply chains and consumers, including related industries (such as the music industry). The 
SmartPhone was able to be adopted within consumer markets due to the size and functionality of the device, but the convergence of previously unrelated industries of mobile telephony, such as computer operating systems and applications was the critical element of the discontinuity of the innovation.

With less than $10 \%$ of new product designs being classified as discontinuous or radical innovation (Griffin, 1997), the question is whether a conventional NPD solely focused on product design is suitable for creation of products that must extend beyond its own physical functionality. Typically, a conventional method of product development, such as StageGate ${ }^{\mathrm{TM}}$, is a combination of linear, structured, processes linked as a closed system, which restricts creativity to a single body (such as a product developer within the OEM firm). One alternative to a linear, closed system process of product development that solely focuses on the product is Buffington's (2010) concept of generative customization (Figure 1 represents its high level logical design) that is more of a framework than a process to develop discontinuous innovation. In this model, it is understood that design and fulfillment factors must extend beyond traditional definitions of new product development (NPD). In a study to understand consumer behavior and innovation, Buffington (2010) found generative customization to be a superior alternative to a traditional NPD design approach for discontinuous innovation. 


\section{Figure 1 - Generative Customization Supply Chain Logical Design}

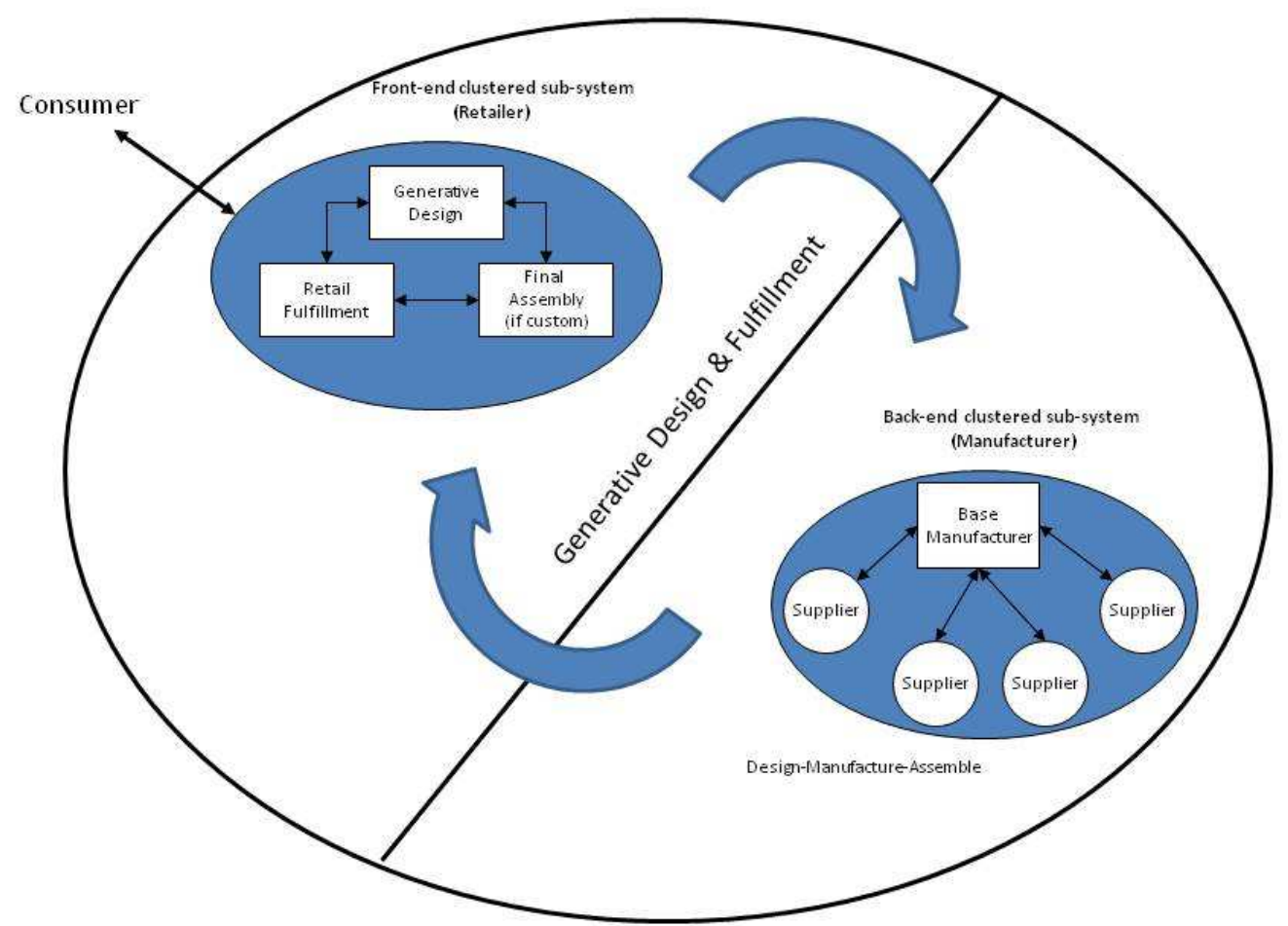

(Buffington, 2010)

The purpose of this study is to build upon this conceptual product design and supply chain fulfillment system of generative customization for discontinuous innovation. This paper will be structured as follows: next, a literature review will be presented discussing generative design and product design (front-end element), agent-based modeling and supply chain network (back-end system), and generative customization as a research concept. Following this literature review, using these concepts a conceptual system design structure will be developed.

\section{Literature Review}

\subsection{Generative Design and Product Design}


Chiva et al (2010) stated that a generative system implies being able to see beyond the situation and questioning operating norms within its environment. Buffington and McCubbrey (2011) expanded upon this point for discontinuous innovations, and found that generativity best serves discontinuous innovation, since it follows a process "on the edge of chaos", which is a necessary condition for the creation of new functionality and markets, beyond the development of a product. Krishnamurti (1994) noted that generative learning requires an individual to focus on intuition and transcendence, which are typically not descriptors used in conventional product design and fulfillment systems; it describes more of a process than an end result. Weick (2007) described generativity as an evocative power or aptitude that is opposite of adaptation. McCormack et al (2004) described as generative design as the production of an artifact and experience, which is difficult to define.

Generative design processes enable complex relationships to form rather than undertaking a linear, reductionist approach and simplifying them for the sake of the supply chain system, or within the inter and intra organizational systems. McCormack et al (2004) found generative design to be defined in terms of dynamic processes and their outcomes. In the use of creative evolutionary systems (CES), entirely new designs can be generated from little or no knowledge guided by the process (Kicinger et al, 2005) rather than the designer. Avital and Te'eni (2009) defines these generative schemes as "simple recipes that allow anyone with basic skills to create or put together", suggesting that "simple instructions will lead to infinite variations". In research and practice, there is scant evidence of its ability to achieve creativity in an 
NPD process beyond a few industries, such as architecture, music and software development. Furthermore, generative design has been utilized solely to develop physical product designs, and to our understanding, has yet to consider definitions of critical processes and relationships to these product designs as well.

The digitization of the design process has become a revolution, and has transformed into a unique field of endeavor, beginning to evolve its own unique methodologies, yet still largely unformulated (Oxman, 2006). While simple applications of Computer Aided Design (CAD) have been in existence as early as the 1960s (Sutherland's SKETCHPAD at MIT), its purpose has been focused almost entirely upon the digitization of form, rather than an improvement on design and market process possibilities. Szykman et al (2001) noted that "traditional CAD systems are limited to representations of geometric data and other types of information relating to geometry such as constraints, parametric information, features, and so on". Hanna and Turner (2006) noted that the focus of CAD is on the representation of the final form described geometrically. LaRocca et al (2002) noted the difference between traditional $C A D$ and generative design being that the latter represents the engineering intent behind the geometric design. Liu et al (2005) acknowledged the progress made in CAD tools over the decades, but noted the large limitations associated with it being able to support human cognition and creativity. Pande and Kumar (2008) developed a generative planning process using computer aided process planning (CAPP) to become a link between CAD and computer aided manufacturing (CAM), further extending possibilities of CAD. 
Generative design is a method that has been implemented in various fields (art, architecture, communication design, product design) where the output is generated by a set of rules or an algorithm, and has a design schema, a means of creating variation and a means of selecting desirable outcomes (Wikipedia, 2010). Therefore, it is different from CAD because it must be based upon modeling knowledge that is created communally on an agreed set of standards (Krish, 2010), as opposed to part of a closed system. In this process, hundreds, or even thousands of design possibilities can be generated through the use of generative schemes and data, which allows a group of designers to change parameters in order to create an innovative design. Therefore, a new design schema is not simply a product of the parameters used to generate it, but rather also includes the conditions used by designers in this process. This is due to the design not being represented in final form, but rather as associative, with changes being enabled through computation (Hanna and Turner, 2006). These communalities of form may also be possible to be extended to communalities of process, to the authors of this paper.

The challenge of generative design is how to frame this human-computer interaction process, for a product-process combination. If generative design adheres to the rules set forth by Simon in his book The Sciences of the Artificial (1996) then the design is contingent upon the goals of the designer and the purposes for which the system is designed. Avital and Te'eni (2008) outlined this human-computer interaction process through the definition of generative capacity (a human's ability to reframe reality and produce something ingenious) and generative fit (an attribute of a system that is 
conducive to evoking and enhancing that generative capacity in people). According to Avital and Te'eni (2008), a system has high generative fit, and can evoke generative capacity if it has the following attributes:

- Visualization (to see an object from multiple perspectives)

- Simulation (to the underlying process or the object's behavior, capabilities, or response to stimuli in different context

- Abstraction (the ability to move swiftly between levels of granularity to identify emergent patterns, commonalities, or anomalies

- Integration (ability to merge views of various parallel subsystems or cross-cuts of objects)

- Communication (one's ability to talk and share information with other agents with no regard to institutionally imposed boundaries

The advancement of theory in generative design is beginning to establish characteristics in evolutionary science. Avital and Te'eni (2008) noted the difference between conventional computer assisted design and generative evolutionary design in being the former specified by predetermined parameters while the latter is focused on the generation or discovery of unique and unexpected solutions. Coblani (2009) developed the concept of Design DNA (DDNA) in the development of generative design.

Given its relative newness as a concept, generative design has significant limitations in research and practice. The discussion of this topic thus far in research has been primarily focused on concepts, or applications in niche industries, such as art and architecture. One concern from literature is that generative design solely addresses the domain of form, texture and color (Krish, 2010), but not functional parameters, or as we have proposed, process parameters as well. In consideration of a discontinuous innovation being defined by the consumer market and peripheral (and perhaps 
perceived as insignificant) players as much as by the product design itself, generative design must be extended in the ex ante definition of future markets as well. This is a critical issue that must be addressed in future research.

\subsection{Agent-Based Modeling in Supply Chain Fulfillment}

Despite business environments changing dramatically over the past two decades (McCarthy, 2006), supply chain systems have been surprisingly static, and diagrammed in very unimaginable ways. In contrast, Koh et al (2006) prescribed that companies in the $21^{\text {st }}$ century will face enormous complexity, and supply chains will need to become more agile and responsive as a prerequisite. Yet supply chain complexity cannot occur in isolation within a supply chain network; Jain et al (2009) found marketing, distribution, planning, manufacturing, and purchasing of organizations along the supply chain operating largely independent of one another, with the organizations having their own objectives and being in conflict with one another. Coordination between multiagent systems (MASs) will stretch the limits of possibilities of how supply chain systems act and evolve, and will require a much greater interaction between the disciplines of supply chain and information technology than ever before.

Therefore, despite the efforts to manage supply chain systems within predictable and linear progressions, supply chains in the $21^{\text {st }}$ century must present themselves as more dynamic and non-linear, leading to endogenous variability being created as companies seek to simplify in this manner. Beyond exogenous factors that are often perceived to be the greatest cause of uncertainty to supply chain systems, endogenous supply chain systems are gaining in complexity as well. Like biological systems, supply 
chain systems possess both endogenous and exogenous forms of variability, and supply chain research hasn't progressed far in understanding how these forms of variability within and from agents in the supply chain impact the entire system. Prater (2005) found that while supply chain uncertainty is a major topic in supply chain literature, there is a tendency to lump various forms of supply chain complexity under a broad concept of uncertainty with few areas of differentiation. Kim's (2007) research validated this notion through stating that while supply chain research focused much attention on the 'bullwhip effect' (order variability impacting upstream systems), and its exogenous impact, less attention has focused on how endogenous variability could lead to exogenous variability. Furthermore, as is the case with discontinuous innovation, uncertainty is not always a factor that must be mitigated; instead, it should often be embraced, and developed.

Various methods for attempting to reduce supply chain uncertainty include improvements in modeling and forecasting different components of the supply chain (Ewing and Thompson, 2008). Moon and Phatak (2005) noted that simulations can often capture and describe the complex interactions within a particular manufacturing or supply chain system where traditional analytical methods fail. On the other hand, mathematical techniques can assist in the development of parameters in a modeling effort, how individual agent characteristics affect a system, and identification of agents to develop an agent-based modeling (ABM) effort (Surana, 2005). Instead of an either or decision, perhaps the most suitable approach is a combination of traditional mathematical techniques for the establishment of agents and a supply chain model, and 
an integrated agent-based modeling tool, establishing less abstract modeling capabilities to understand and patterns issues of complexity and uncertainty. Surana (2005) found a useful amalgam of simulation and analytical techniques for the use of understanding and predicting supply chain systems.

However, there are limitations in the use of agent-based modeling in supply chain systems. One, simulations are developed offline and separate from enterprise software packages (Yoon and Shen, 2006), limiting observations to single event analysis. Moon (2005) found that traditional simulation models are usually not built for repetitive and continuous usage partially due to the laborious data collection process. Difficulty in automatic collection of data and continuous update of the data for the built simulation model discourages further usage of the initial model. In their study, Al-Zubaidi and Tyler (2004) noted a major requirement of the simulation model is that it should capture the dynamic and stochastic nature of consumer behavior at the retail store, which is not possible without easily accessible and usable operational data.

Similar to the use of generative design in product design processes, the use of ABM in the dynamic development of supply chain networks is in its infancy stages.

\subsection{Generative Customization}

Buffington and McCubbrey (2011) identified a major problem in the development of the generative customization concept being that while the front-end product design process could occur through the use of generative design processes and tools (Proposition $\mathrm{P}_{3}$ ), there are no new product development (NPD) processes established for the fulfillment of this design in a mass market supply chain system. Given the 
intuitive, creative, and largely unstructured approach of generative design, often avoiding the final form of the product design (Garud, et al, 2008), there are inherent problems in the identification of peripheral agents involved in a discontinuous innovation, future markets, and the fulfillment of the product as a result. In an expertbased approach to design that is represented in discontinuous innovation (Sanders, 2008), a collaborative process including the consumers and suppliers (some who are agents unknown) has not been found to be viable.

Numerous researchers, such as Danneels (2004) have found that consumers are almost never able to conceive a radical (or discontinuous) innovation, and their involvement in such a process is inefficient. Given this limitation, which is so critical in a dynamic supply chain system, the possibility of creating a virtual consumer and supplier, via generative design and agent-based modeling, has been proposed in generative customization as a compromise in the lack of a collaborative environment. For this purpose, the use of agent-based modeling techniques can be proven as useful in the establishment of how these products, processes and agents interface with one another in the creation of a discontinuous innovation.

In the development of a generative customization product design and supply chain fulfillment system, the inability to achieve collaboration as a function of the design of the product and process using generativity (creatively and separate from existing consumers and suppliers) poses an immense challenge for the achievement of discontinuous innovation. Danneels (2004) and Govindarajan and Kopalle (2006) both noted a firm's reluctance to pursue discontinuous innovation as a function of its inability 
to more accurately predict its potential for success in a marketplace, ex ante. Outside of the use of structured (not necessarily linear) NPD processes and tools, we question how this research problem can be achieved, which leads to our model for generative customization as a set of NPD processes and tools for discontinuous innovation.

\section{The Use of Generative Design and Agent-Based Modeling in Generative Customization}

Through a definition of discontinuous innovation and the literature review of generative design, agent-based modeling, and generative customization, a three step process requirement will be established in this paper for the use of generative customization in the development of discontinuous innovation, as is shown below in Table 1. These steps in the process will be discussed through the product design process for generative customization, as will be discussed in this section.

Table 1 - Generative Customization Product Design and Fulfillment Methodology

\begin{tabular}{|c|l|l|}
\hline Step & \multicolumn{1}{|c|}{ Definition } & \multicolumn{1}{c|}{ Explanaton } \\
\hline $\begin{array}{c}\text { Product Variation } \\
\text { (variate) }\end{array}$ & $\begin{array}{l}\text { The modification of the digital } \\
\text { representation of an existing product, or } \\
\text { the creation of an entirely new invention } \\
\text { (Generative Design). }\end{array}$ & $\begin{array}{l}\text { Establishing a product design as a process (artifact } \\
\text { and experience) rather than an invention in final } \\
\text { form. }\end{array}$ \\
\hline $\begin{array}{c}\text { Non Product } \\
\text { Variation } \\
\text { (variate) }\end{array}$ & $\begin{array}{l}\text { Starting with the base of a new product } \\
\text { artifact, the use of generative design to } \\
\text { develop non-product factors (agents and } \\
\text { processes) for discontinuous innovation. } \\
\text { These may be peripheral products or } \\
\text { services. }\end{array}$ & $\begin{array}{l}\text { If the product design is an artifact and experience } \\
\text { (product variation), it will be extended in definition } \\
\text { beyond the physical product to include other factors } \\
\text { and markets. }\end{array}$ \\
\hline $\begin{array}{c}\text { Market Equilibrium } \\
\text { Agent Model } \\
\text { (MiEAM) }\end{array}$ & $\begin{array}{l}\text { Agent-based process that simulates the } \\
\text { product and market variations in the } \\
\text { achievement of new markets and } \\
\text { peripheral agents (suppliers of products } \\
\text { and services), enabling firms to conduct ex } \\
\text { ante predictions. }\end{array}$ & $\begin{array}{l}\text { Fusing generative designed product and non-product } \\
\text { features in the development of generative } \\
\text { customization. Both product design, and fulfillment } \\
\text { parameters are created. }\end{array}$ \\
\hline
\end{tabular}

Schumpeter (1950) found a disruptive or discontinuous innovation process to commence from a market in a state of equilibrium, with a disruption (or multiple) 
converging upon the environment, creating a transformational change to the consumer, supplier, market and the product (not just to the design of the product). Since incumbents in a current market environment are generally comfortable with stability and equilibrium, the goal of the generative customization system will be to interject an element of disruption into the system to enable radical innovation.

In the first step, the product designer will develop completely new product invention designs, or mutations of products from existing designs using generative design techniques. Through an associative, digital definition of the parameter form, the designer is able to make modifications to product parameters (represented in digital form), developing virtually an unlimited number of design permutations. Through this first step, a product invention has been achieved through the process, but not a product innovation, as these forms have been yet to be found as useful to a future consumer market. Given that discontinuous product designs (inventions) can often be a convergence of components from different products (such as a Smartphone being a convergence of a telephone, computer, and personal audio player, for example), generative design must transform the function as well as form parameters in design, which is relatively unproven in its history.

Using this first stage (product variation), generative design techniques are used to create non-product parameters to enable the product invention. If the first stage is considered the traditional core product design, the non-product variation can be the development of peripheral products and services to support the core invention. Continuing to use the Smartphone as an example, a wireless headphone and car MP3 
player are examples of peripheral product developments, as is the case of mobile applications, personal GPS, and Internet based delivery sites. The non-product developments of a discontinuous innovation can become more prolific to a consumer market potential than the core invention itself. Through the use of creative generative design principles, these possibilities can be created as a function of the core product development.

As Schumpeter (1983) noted, there is a difference between a product invention and innovation, with an innovation being a function of the market environment. From Garcia (2007), the market environment for discontinuous innovation will be defined in terms of two heterogeneous agents, as follows:

1) Future Consumer Adoption = $f$ (individual preferences, consumer network effects, firm adoption, advertising)

2) Future Firm and Supply Chain Adoption $=f$ (innovativeness, firm network effects, consumer adoption)

The development of a discontinuous innovation requires a combination of a new product invention, a new consumer market, and/or a new firm and supply chain. As an example, the development of a digital audio player is not useful without the development of a compressed audio file format, the development of online sources as a delivery mechanism, and other factors unrelated to the development of a portable audio player with a computer hard drive. As such, the development of the electronic component and these peripherals operate as an open innovation system (Chesbrough, 2003), with all consumers and suppliers are modeled in a market equilibrium agent model (MEAM), as opposed discrete and linear consumer and supplier agents solely 
involved in an existing supply chain system. The MEAM process will define the third step of generative customization, to model both the product invention and the development of the market into one discontinuous innovation process.

As is shown in Figure 2, the third step will establish a product design and supply chain fulfillment model, created as a market equilibrium agent model (MEAM), to dynamically interface the product and non-product clusters to establish the discontinuous innovation.

Figure 2 - Market Equilibrium Agent Model (MEAM)

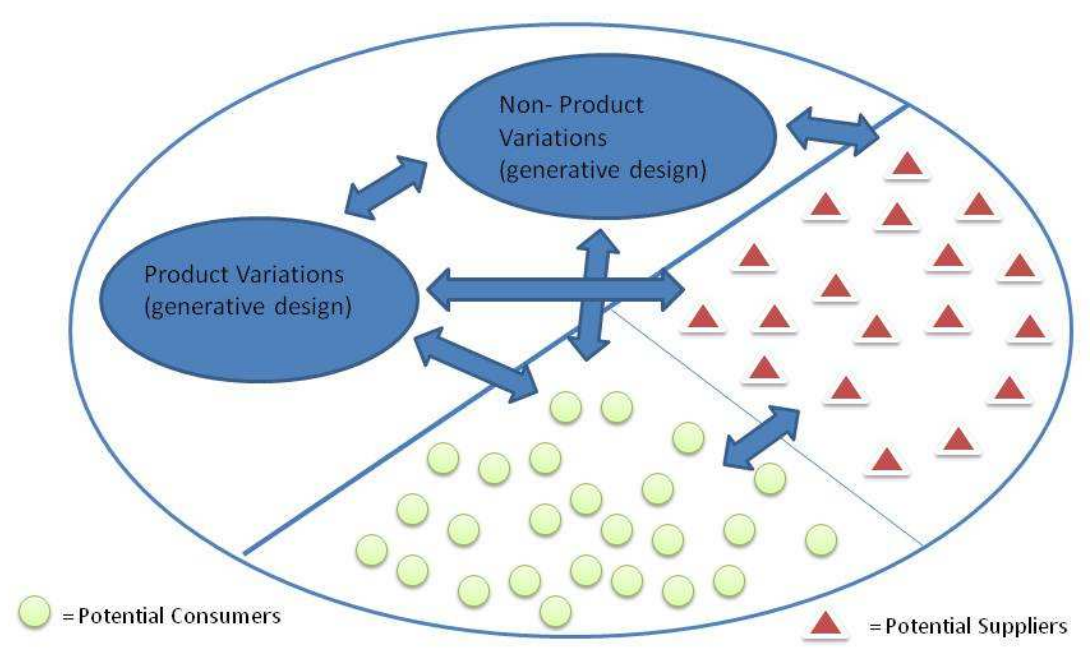

The variation processes provides the definitions of the product and non-product parameters to be established via associative definitions, not defined in final form. The ability to variate both the product and non-product components/parameters do not appear to have a precedent in extant research, and needs to be explored in future research. While Krish (2010) discussed the variation of a limited range of products 
Figure 3 - Discontinuous Innovation Diffusion Model

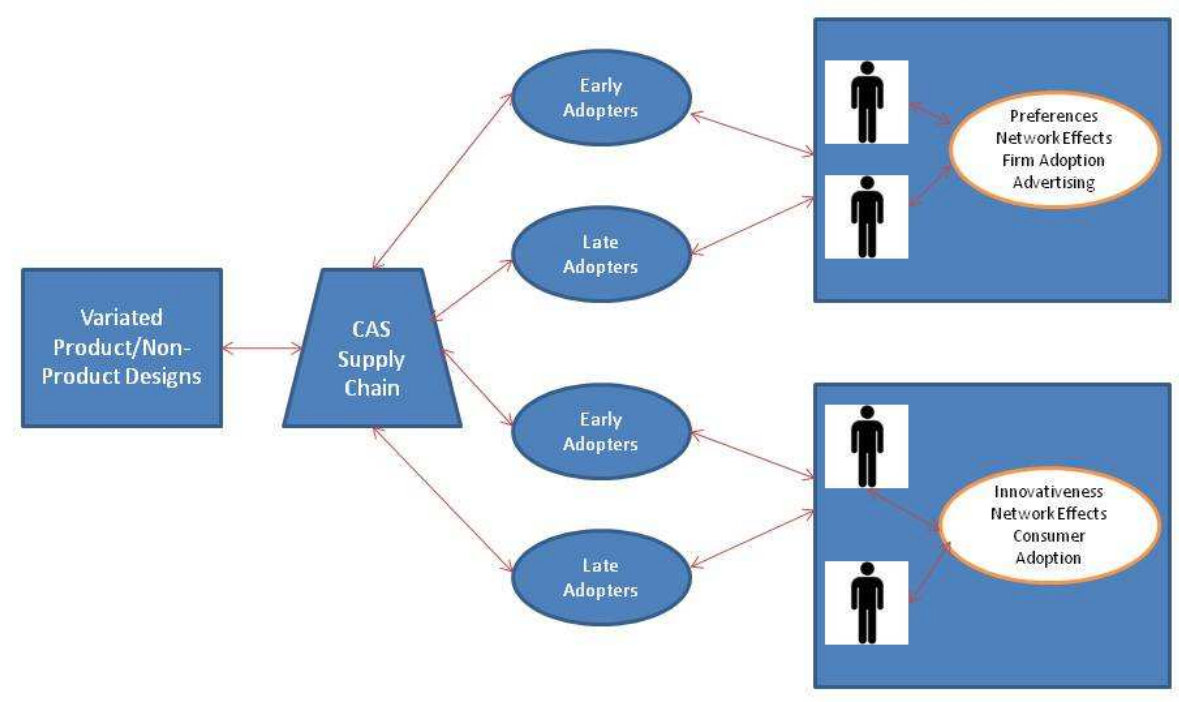

The goal of this agent based model is to simulate an amended diffusion of innovation process, based upon Rogers (1962) model, but existing of a complex adaptive system (holistic) view of diffusion, not just related to the consumer. A fallacious assumption in discontinuous innovation is that only the consumer needs to adopt and change in this process, but in reality, diffusion needs to occur in various, and unstructured ways within 
the stakeholders in the process, often newly created and involved. In this case, market equilibrium exists in a heterogeneous agent mode (Figure 2), that includes not just consumers and suppliers for the existing product, but including suppliers and consumers within the market, not necessarily involved in the current environment, but influencing, as is suggested in complex adaptive systems and open system (Chesbrough, 2003) theory. It is critical in an establishment of the MEAM, as shown in Figure 2, to represent the entire possible market, not just the existing supply chain, given that discontinuous innovation is the disruption of an existing market to the creation of new consumers, suppliers and market conditions; given the difficult of ex ante predictions, this is a difficult, unstructured step. As a result of this process, a supply chain system emerges and self-organizes, based upon the definition of the product design. As a result, a radical invention is transformed into a discontinuous innovation through the result of the efficient fulfillment of the product design.

The simulation of the variated product into the MEAM is the introduction of an invention into this market equilibrium to understand the nature of the disruption, as shown in the below mathematical problem:

$$
D I_{x}=f\left(P I_{x}, N P_{x}, C x, S_{x}\right)
$$

Where,

$\mathrm{DI}_{\mathrm{x}}=\mathrm{A}$ definition of discontinuous innovation solutions, as a result of the interaction between the variables (to define an ex ante consumer market and peripheral agents).

| $\quad \mathrm{PI}_{\mathrm{x}}=$ An introduction of a discontinuous product invention

$N P_{x}=$ An introduction of a discontinuous non-product invention

$C_{x}=A$ definition of the consumer response, as noted by Garcia (2007)

$S_{x}=A$ definition of supplier's response, as noted by Garcia (2007) 
Therefore, the product designer must establish numerous simulations of this process, because the difference between an invention and an innovation is the relationship that the product has with its environment, as noted in the following proposition:

Proposition $_{D I}$ : The development of a discontinuous innovation via generative customization occurs through the dynamic interaction between product and nonproduct parameters, which have been developed and interacted through a generative and agent-based modeling simulation process.

From this process, an ex ante prediction process can occur to measure the potential of a discontinuous innovation, a process that is not possible today (Danneels, 2004). This dynamic environment will model the nature of a discontinuous innovation itself, and provide the firm with an improved structural framework to make new product development decisions.

\section{Conclusions}

The cruel irony facing firms when considering the development and implementation of discontinuous innovation is while there appears to be a greater frequency and severity of its occurrences of late (Birkinshaw et al, 2006), the process and risk associated with doing it remains greater than ever. When faced with the consideration of a radical innovation strategy through the use of conventionally linear and finite tools (even including CAD systems), the cliché going to a gunfight with a knife can often come to mind by firms, leading them to play it safe through incremental innovations, or staying safely (at least for the time being) within the comfortable confines of the market equilibrium. 
The problem posed in this research paper, and in Buffington's (2010) definition of generative customization, is how to utilize the capabilities of computer technology and creative human cognition to improve the capabilities of seeking and achieving discontinuous innovation in product design. After a review of extant literature, a system design has been developed that achieves this purpose, at least in concept. This was accomplished through using the emerging technologies of generative design and agentbased modeling to create discontinuous innovation both in the form of a product design, supply chain process, the identification of future markets, and of new agents involved in the process.

Through the development of a three step generative customization methodological process, as is shown in Table 1, the fusion of generative design and agent based modeling was accomplished in the steps of product variation, non-product variation, and interaction is fashioned for the achievement of generative fit, as noted in Avital and Te'eni (2008). Therefore, the goal of this generative customization methodology is not in the achievement of a discontinuous design of a product, per se, but rather in the development of all parameters necessary for the development of a future consumer market. From this, Proposition $_{\mathrm{DI}}$ is introduced that defines discontinuous innovation as a function of a dynamic interfacing between these product and non-product parameters to improve the predictive nature of it. We believe that this is an original and significant finding in the measurement and development discontinuous innovation that is only possible through these emerging tools (and not possible through the use of linear tools, such as differential equations). 


\section{Future Research}

To our knowledge, this is the first study that seeks to integrate the use of generative design and agent based modeling in the understanding, development and measurement of discontinuous innovation. While there has been some research related to agent based modeling and supply chain systems, and scarce, but some in relation to generative design and NPD, there needs to be a further examination of these factors, both separately and in conjunction with one another. Future studies can be individual case studies, surveys within an industry related to NPD practices, and modeling and simulations of this concept.

\section{References}

Al-Zubaidi, H., Tyler, D. (2004) "A simulation model of quick response replenishment of seasonal clothing", International Journal of Retail \& Distribution Management, Vol. 32 Iss: 6, pp.320 - 327

Avital, Michel, and Dov Te'eni. (2009). "From generative fit to generative capacity: exploring an emerging dimension of information systems design and task performance". Information Systems Journal. 19 (4): 345-367.

Balakrishnan, P. V., and Jacob, V., (1996). "Genetic Algorithms for Product Design". Management Science. 42 (8): 1105-1117.

Birkinshaw, Julian, John Bessant, and Rick Delbridge. 2007. "NETWORKS - Finding, Forming, and Performing: Creating Networks for Discontinuous Innovation". California Management Review. 49 (3): 67.

Boden, M. The Creative Mind: myths and mechanisms. London Cardinal, 1992. Bruderer, E., and Singh, J. (1996). Organizational Evolution, Learning and Selection: A Genetic Algorithm Based Model. Academy of Management Journal 39:1322-49 (October).

Buffington, J. (2010). Development of Generative Customization for Consumer Mass Markets. , Industrial Management and Data Systems, Volume 111 (1), October.

Buffington, J. and McCubbrey, D. (2011). A Conceptual Framework of Generative Customization as a Solution for Product Innovation Conceptualization and Fulfillment, European Journal of Innovation Management, forthcoming. Chesbrough, H. (2003). Open innovation: The new imperative for creating and profiting from technology. Boston, Mass: Harvard Business School Press. Chiva et al (2010). Adaptive and Generative Learning: Implications from Complexity 
Theories. International Journal of Management Reviews. Pp114-129.

Coblani, O. (2009). Generative Design Using the Design DNA. $12^{\text {th }}$ Generative Art Conference.

Danneels, E. (2004). Disruptive Technology Reconsidered: A Critique and Research Agenda. Journal of Product Innovation Management, 21, 4, 246-258.

Ewing B., and Thompson M., (2008). "Industrial production, volatility, and the supply chain". International Journal of Production Economics. 115 (2): 553-558.

Garcia, R. (2007). "Co-opetition for the Diffusion of Resistant Innovations: A Case Study in the Global Wine Industry using an Agent-based Model".

Garud, R., Jain, S., and Tuertscher, P. (2008), Incomplete by Design and Designing for Incompleteness, Organization Studies, Vol.29 (3), pp. 351-371.

Griffin, A. (1997). PDMA Research on New Product Development Practices: Updating Trends and Benchmarking Best Practices. Journal of Product Innovation Management 14(6):429-458.

Govindarajan, V., \& Kopalle, P. K. (2006). The Usefulness of Measuring Disruptiveness of Innovations Ex Post in Making Ex Ante Predictions. Journal of Product Innovation Management, 23, 1, 12-18.

Hanna, S. and Turner, A. (2006). Teaching Parametric Design in Code and Construction. Educacion y Desarrolio Academico.

Jain V., Wadhwa S., and Deshmukh S.G. (2009). "Select supplier-related issues in modelling a dynamic supply chain: Potential, challenges and direction for future research". International Journal of Production Research. 47 (11): 3013-3039.

Kicinger, R., Arciszewski, T., \& Jong, K. D. (2005). Evolutionary computation and structural design: A survey of the state-of-the-art. Computers \& Structures. 83 (23), 1943.

Kim, J., Chatfield, D., Harrison, T., and Hayya., J. (2006). "Quantifying the bullwhip effect in a supply chain with stochastic lead time". European Journal of Operational Research. 173 (2): 617-636

Koh, L., Saad, S. and Arunachalam, S. (2006) "Competing in the 21st century supply chain through supply chain management and enterprise resource planning integration", International Journal of Physical Distribution \& Logistics Management, Vol. 36 Iss: 6, pp.455-465

Krish, S. (2010). Generative Design, found at: http://generativedesign.wordpress.com/

Krishnamurti, J. (1994). On learning and knowledge. [San Francisco]: HarperSanFrancisco.

LaRocca, G., Krakers, M., van Tooren, L. (2002) Development of an ICAD Model for Blended Wing Body Aircraft Design., Symposium on Multidisciplinary Analysis and Optimization, September.

Liu, H., L. Gao, and X. Liu. (2005). "Generative Design in an Agent Based Collaborative Design System". Lecture Notes in Computer Science. (3168): 105116.

MacCormack, A., and Verganti, R. (2001). Managing the sources of uncertainty: 
matching process and context in new product development. [Boston]: Division of Research, Harvard Business School.

McCarthy, I. P., Tsinopoulos, C., Allen, P., \& Rose-Anderssen, C. (2006). New Product Development as a Complex Adaptive System of Decisions. Journal of Product Innovation Management, 23, 5, 437-456.

Moon, Y., and Phatak, D. (2005) "Enhancing ERP system's functionality with discrete event simulation", Industrial Management \& Data Systems, Vol. 105 Iss: 9, pp.1206 1224

Oxman, R. 2006. "Theory and design in the first digital age". Design Studies. 27 (3): 229-265.

Pande, S., and Kumar, S. (2008). A generative process planning system for parts produced by rapid prototyping. International Journal of Production Research. 46 (22): 6431-6460.

Prater, E. (2005). "A framework for understanding the interaction of uncertainty and information systems on supply chains". International Journal of Physical Distribution and Logistics Management. 35 (7): 524-539

Rogers, E. M. (1962). Diffusion of innovations. New York: Free Press.

Sanders, L. (2008). An Evolving Map of Design Practice and Design

Research. Interactions New York-, 15, 6, 13-17.

Schumpeter, J. A. (1950). In Capitalism, socialism, and democracy. New York: Harper. Simon, H. A. (1981). The sciences of the artificial. Cambridge, Mass: MIT Press.

Surana, A., Kumar, S., Greaves, M., and Raghavan, U.N. (2005).

"Supply-chain networks: a complex adaptive systems perspective". International Journal of Production Research. 43 (20): 4235-4265

Szykman, S., Fenves, S., Keirouz, W. and Shooter, S. 2001. "A foundation for interoperability in next-generation product development systems". Computer Aided Design. 33 (7): 545-559.

Weick, K. E. (2007). The Generative Properties of Richness. Academy of Management Journal,50, 1, 14-19.

Wikipedia (2010), Generative Design, found at: http://en.wikipedia.org/wiki/Generative Design

Yoon, H. J., and W. Shen. 2006. "Simulation-based real-time decision making for manufacturing automation systems: a review". International Journal of Manufacturing Technology and Management. 8 (1/2/3): 188-202 